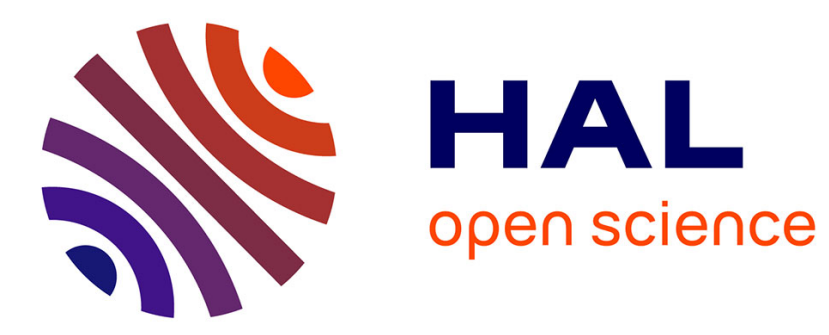

\title{
Influence of the frequential identification tests on the induction machine modelling
}

\author{
M. Belhaj, P. Guérin, M.E. Zaïm, L. Abdeljalil
}

\section{To cite this version:}

M. Belhaj, P. Guérin, M.E. Zaïm, L. Abdeljalil. Influence of the frequential identification tests on the induction machine modelling. European Physical Journal: Applied Physics, 2009, 47 (3), pp.1-10. 10.1051/epjap/2009099 . hal-00489488

\section{HAL Id: hal-00489488 \\ https://hal.science/hal-00489488}

Submitted on 5 Jun 2010

HAL is a multi-disciplinary open access archive for the deposit and dissemination of scientific research documents, whether they are published or not. The documents may come from teaching and research institutions in France or abroad, or from public or private research centers.
L'archive ouverte pluridisciplinaire HAL, est destinée au dépôt et à la diffusion de documents scientifiques de niveau recherche, publiés ou non, émanant des établissements d'enseignement et de recherche français ou étrangers, des laboratoires publics ou privés. 


\title{
Influence of the frequential identification tests on the induction machine modelling
}

\author{
M. Belhaj, P. Guérin, M. E. Zaïm and L. Abdeljalil
}

patrick.guerin@univ-nantes.fr

\section{Key word: induction machine, frequential identification}

Institut de Recherche en Electrotechnique et Electronique de Nantes Atlantique (IREENA), 37 bd de l'université, BP 406, 44602, Saint Nazaire, France.

An electric network is constituted by generators providing power to various loads. The induction machine is the most common motor in the industrial applications because of its simplicity of construction, its reliability and its low cost. It allows the constant speed applications when it is directly supplied by the network and variable speed ones with the use of power converters. These speed drives induce important harmonic perturbations in the power system and in the motor side. In this context, we are interested by the frequential modelling of the induction machine in order to simulate the line current with its harmonic components. In order to use the induction machine models, it is necessary to identify their parameters and therefore realizing specific and sufficiently informative tests. Several tests of identification are presented in the literature; their differences and their relevance have not been discussed. This study deals with the realization and the comparison of several types of frequential tests (constant voltage, constant V/f, injection of DC current) for induction machine models identification. The comparison of the simulation results with the experimental measurements allows electing the most representative of the induction machine behaviour. 


\section{Introduction}

With the widespread use of power electronics in the electrical equipments, the absorbed currents are less and less sinusoidal. The number and the unit power of the non-linear loads lead to network voltage disturbance, especially due to the injection of the harmonic perturbations. In the context of a decentralized production, with the possibility of isolated working, these phenomena are easily increased and can then seriously compromise the quality and the availability of the distributed energy. From these different facts, there is an interest of analyzing accurately the interactions between the non-linear loads and the power system.

The induction machine is the most common motor in the industrial applications. It allows the constant speed applications when it is directly supplied by the network and variable speed ones with the use of power converters. These speed drives induce important harmonic perturbations in the power system and in the motor side.

Consequently, the analysis and the simulation of low frequency disturbances $[50 \mathrm{~Hz}-1 \mathrm{kHz}]$ require an adapted modelling of the machine and its supply. This paper proposes a circuit type frequential model of the induction machine in view of the electrical network simulation. This model allows the reproduction of the main low frequency components of the line current when the machine is supplied by non-sinusoidal voltages.

Some of the models studied in the literature use integer orders based on resistances and inductances circuits in parallel or in ladder [1], [2]. Others use non integer orders based on the integration of fractional order impedance in the rotor circuit [3], [4]. In [5] various induction machine models are compared and their performances and their validity domains are discussed.

In order to use any model, its parameters have to be easily determined. In the literature [1], [4], [6] and [7], several procedures of identification tests are proposed. They are realized with blocked rotor (harmonic excitation). Among these measurement methods, it is necessary to choose the most representative, thus, the one that allows the parameters determining in the nearest conditions to the machine real working.

The aim of this work is identifying the best method, thus each one is studied and its representativity is tested using an experimental benchmark. Which is constituted by an industrial $5.5 \mathrm{~kW}$ induction machine and its variable speed drive. This benchmark allows observing the real phenomena appearing in the machine supplied by non sinusoidal voltage. It is also useful as reference in all the identification phases and for the models validation.

The first part of this paper presents briefly the methods of the induction machine frequential modelling presented in the literature. The most representative model will be used for the identification methods comparison [5]. 
In the second part, the identification measurements are treated. We begin by the description of classical and frequential tests. The measurement methods are then compared and the machine representativity is discussed. The effect of the induction machine non-linearity on the frequential behaviour and the importance of the magnetic flux level during the tests are highlighted.

In the last part, a genetic algorithm is used to determine the parameters of the machine model. The line current computed by the induction machine model is compared to the measurements for each identification method and the efficiency of the various identification measurements is discussed.

\section{Frequential modelling of the induction machine}

Concerning the induction machine modelling, several studies have showed that the generalized equivalent circuits are necessary for harmonic analysis [2], [8], [9]. In this context, these models take into account the frequency effect and two families can be identified :

- Integer order models [10], [11]: They are based on the fundamental model of the induction machine with the rotor conductors represented by RL cells representing the massive conductor [2], [12].

- Non integer order Models [2], [4], [13] : The application of non integer orders in machine modelling has been used in several studies [14], [15]. The frequency effect on the single bar impedance is studied in [16] with a non integer order modelling. In [17], this approach is extended to the complete model of the induction machine by including a non integer order representation of the rotor.

Otherwise, a model based on the superposition principle and taking into account the influence of the voltage supply has been studied in [5]. One part of the model is used to describe the fundamental behaviour of the induction machine and another one represents the harmonic contributions (Fig 1). The summation of the resulting currents gives the machine line current. The fundamental component is represented by the classic single-phase model of the induction machine (Fig 1_a). The harmonic components are obtained with the help of RL circuits representing the massive conductor behaviour[2][12] (Fig 1_b). The superposition principle induces that the fundamental and harmonics phenomena are independent. The advantage of this model is to eliminate the harmonic influence if the induction machine is supplied by pure sinusoidal voltages. Moreover, the experimental identification tests of the two parts of the model, fundamental and harmonics, are completely dissociated. The fundamental model parameters can be identified by usual measurements at no load and at blocked rotor for the nominal frequency of the machine. The harmonic model must be determined with another specific experiments that must be enough informative. According to the study in [5], this model represents correctly the induction 
machine frequential behaviour around its operating point thus, it will be used in the following for comparing the identification methods.

\section{Measurement methods in view of the induction machine frequential models parametrical identification}

It is clear that the frequential behaviour of the machine is better described using a frequential approach than a temporal approach [18]. Indeed, the frequential approach is generally on the one hand easier to apply and it represents less risk for the machine compared to some temporal responses like a step response. On the other hand, the measurements are less sensitive to the noise because the sinusoidal signals are defined at a given frequency and they can be easily decorrelated from the noise.

In the literature [1], [4], [6], [7], several tests are used to characterize the frequential behaviour of the induction machine. They are called harmonic excitation tests and are frequently realized with blocked rotor. They lead to the identification of the machine single phase impedance and they describe its evolution according to the frequency. The first one consists in imposing a sinusoidal voltage with constant amplitude and variable frequency. The second test is the SSFR method (StandStill Frequency Response) which imposes constant voltage-frequency ratio. Finally, the third test is based on the injection of a sinusoidal current with a DC component for increasing the magnetic flux in the machine.

\subsection{Constant voltage and variable frequency}

This experiment is done with a blocked rotor and the stator is supplied by a sinusoidal reduced voltage with constant magnitude and variable frequency [1]. Before realizing the measurement, it has been verified that the rotor position has no impact on equivalent induction machine impedance.

Usually, these low voltage tests $(<1 \mathrm{~V})$ are realized with an impedance analyzer [1], [19]. Thus, the impedance variation of our induction machine has been then measured with an impedance analyzer (HP4192A) for a supply voltage of $0.5 \mathrm{~V}$. In order to realise tests with higher voltages, a three phase controlled voltage source has also been employed. Finally, three tests have been realized for three voltages $\left(V_{1}=32 \mathrm{~V}, \mathrm{~V}_{2}=16 \mathrm{~V}, \mathrm{~V}_{3}=0.5 \mathrm{~V}\right)$ and for a frequency range of $[40 \mathrm{~Hz}-1 \mathrm{kHz}]$. The variations of the neutral to phase impedance are presented in Fig 2.

For $\mathrm{V}_{3}=0.5 \mathrm{~V}$, the impedance evolution is similar whatever the measurement device is: impedance analyzer or controlled voltage source. The impedance norm increases in quasi linear manner. Nevertheless, for the tests at $\mathrm{V}_{1}=32 \mathrm{~V}$ and $\mathrm{V}_{2}=16 \mathrm{~V}$, the norm increases in a non linear way with a changing slope. This non linearity has been 
mentioned in [1], but it has not been discussed because the studied tests were only made at low voltages with an impedance analyzer.

Before explaining the phenomenon, it is important to note that the observed non linearity is difficult to analyze when the magnetic hysteresis phenomenon is taken into account [6]. The measured impedance value would also depend on the machine initial state, so it would depend on its last magnetization point. In order to minimize the influence of this phenomenon, we have supplied the machine before each test by a sine voltage at $50 \mathrm{~Hz}$ before decreasing progressively the current until the retentive effect becomes very low. Thus the hysteresis will be neglected in the following analysis.

Considering the evolution of the magnetic permeability of various steels used in the electrical machines (Fig. 3), we observe that the permeability increases first in a non linear way, reaches a maximum localised in an area usually considered linear and then decreases asymptoticly as when the machine saturates.

The no load operating point of the induction machine is localized at the saturation elbow level (around the point $\mathrm{M}_{1}$ corresponding to $\mathrm{H}=300 \mathrm{~A} / \mathrm{m}$ and $\mu_{\mathrm{r}}=3400$ ) (Fig. 3) which corresponds to a voltage/frequency ratio of $230 / 50(\mathrm{~V} / \mathrm{Hz})$

The blocked rotor tests for all the voltages are done with a lower (V/f) ratio than 230/50. Indeed the maximal V/ f values are equal to $32 / 40,16 / 40$ and $0.5 / 40$. Thus, the corresponding magnetic flux is low. The measured points at $40 \mathrm{~Hz}$ are localized in an area of low field between points $M_{3}$ and $M_{n}$ (Fig. 3). When the frequency increases the magnetic state moves towards $M_{n}$. Thus, the non linearity which appears in Fig 2 can be explained by the first material magnetization characteristic.

The non linear evolution of the permeability influences necessarily the machine equivalent impedance. We have seen that the realized tests correspond to the first part of permeability curve $\left(\mathrm{M}_{3} \rightarrow \mathrm{M}_{4} \rightarrow \mathrm{M}_{\mathrm{n}}\right)$. For high frequencies, the permeability becomes very low (point $\mathrm{M}_{\mathrm{n}}$ ). During the measurements, the machine impedance increases with the frequency and consequently the current and the magnetic field decrease.

In the area $\mathrm{H}_{\mathrm{n}}<\mathrm{H}<\mathrm{H}_{3}$, the permeability decreases, the magnetic leakage increases and :

- The dispersion coefficient $\left(\sigma=1-\frac{\mathrm{M}^{2}}{\mathrm{~L}_{1} \mathrm{~L}_{2}}\right)$ increases. $\mathrm{M}$ is the stator rotor mutual inductance and $\mathrm{L}_{\mathrm{i}}$, is the cyclic inductance ( $\mathrm{i}=1$ for stator and $\mathrm{i}=2$ for rotor).

- The leakage inductance $\mathrm{N}_{\mathrm{r}}^{\prime}=\frac{1}{\mathrm{~m}^{2}} \sigma \mathrm{L}_{2}$ increases.

- The relation $\mathrm{m}=\frac{\mathrm{M}}{\mathrm{L}_{1}}$ decreases. 
- The rotor resistance seen from the stator equal to $R_{r}^{\prime}=\frac{R_{r}}{m^{2}}$ increases.

The leakage inductance and consequently the imaginary part of the machine equivalent impedance increases according to the frequency until a value of the magnetic excitation $\left(\mathrm{H}=\mathrm{H}_{\mathrm{n}}\right)$ for which the permeability variation becomes small. This phenomenon can explain the non linearity observed between 100 and $400 \mathrm{~Hz}$ on the neutralphase impedance norm (Fig 2). In addition, when the frequency increases, the skin effect in the magnetic steel leads to the machine equivalent inductance decreasing. This phenomenon can be seen in Fig 4 where the equivalent inductance evolution shows a diminution from $400 \mathrm{~Hz}$ for the test at $\mathrm{V}_{1}=32 \mathrm{~V}$ and from $200 \mathrm{~Hz}$ for $\mathrm{V}_{2}=16 \mathrm{~V}$.

During the test with low voltage $\mathrm{V}_{3}=0.5 \mathrm{~V}$, the magnetic field is very low for all the frequency values and consequently the permeability remains practically constant. Thus, the field has a weak influence on the impedance variation according the frequency. However, this low voltage corresponds to a magnetic state far from the nominal operating point of the induction machine. Concerning the tests at $\mathrm{V}_{1}=32 \mathrm{~V}$ and $\mathrm{V}_{2}=16 \mathrm{~V}$, the permeability varies and consequently the parameter identification can not be representative of a single state of the induction machine.

\subsection{Standstill Frequency Response test $(\mathrm{V} / \mathrm{f}=\mathbf{c s t})$}

From the analysis of the previous measurements, it seems necessary to keep the same magnetic state in all the frequency bandwidth in order to identify the machine frequential behaviour without introducing the supplementary variations relied to the material characteristics.

The SSFR method (Standstill Frequency Response) [6] is used to determine the frequential characteristics of the blocked rotor machine. The stator is supplied by a sinusoidal voltage source with variable amplitude and frequency (Fig 6). The ratio V/f is kept constant when the frequency varies. Thus the current amplitude is nearly steady. The method is normalized for the synchronous machine identification and adapted for the induction machine after some simplifications [20][21][22]. Indeed, the induction machine rotor is symmetrical, so no rotor positioning is required and it is not necessary to separate the measurement of operational direct and quadrature impedances. Moreover, since the induction machine does not have excitation winding, there are no measurements in the rotor.

The three-phase source used previously is well adapted to the SSFR because it can deliver low voltages at low frequencies and relatively high voltages at high frequencies. This controlled voltage source can then imposes a 
constant $\mathrm{V} / \mathrm{f}$ ratio. If the stator resistance is neglected, the magnetic flux is considered as steady in the machine. The magnetic permeability is then independent on the frequency (Fig 7).

Since the choice of the ratio (V/f) can have an influence on the machine impedance, tests have been realized for various values comprised between 50/1000 and 100/500 [V/Hz]. Compared to the nominal point value 230/50 these ratios correspond to operating points localized between the points $M_{3}$ and $M_{n}$ (Fig. 3). The evolution of the norm and the argument of the phase-neutral impedance depending on the frequency are presented in Fig 5 for four $\mathrm{V} / \mathrm{f}$ values.

It appears that the non linearity observed during the identification tests with constant voltage (Fig 2) is not present in the SSFR measurements. The machine equivalent inductance depending on the frequency (Fig 7) corresponds to a $1 / \sqrt{\mathrm{f}}$ behaviour, according to the skin effect in a massive conductor [5].

The usual V/f ratios employed in the SSFR method tests are low. This induces a weak flux compared to the nominal one. In order to increase the flux, the V/f ratio must be increased. But nominal ratio is not allowed when the machine has a blocked rotor. Indeed, at $\mathrm{V} / \mathrm{f}=30 / 40$ (nominal ratio 230/50) the machine already absorbs its nominal current of $10 \mathrm{~A}$. When the frequency varies from $50 \mathrm{~Hz}$ to $1 \mathrm{kHz}$, the voltage source must supply a higher voltage varying between $30 \mathrm{~V}$ and $750 \mathrm{~V}$.

Knowing that the $\mathrm{V} / \mathrm{f}$ variations have an important impact on the operational impedance variation, this kind of measurement remains insufficient to represent the nominal behaviour of the machine.

\subsection{SSFR test with DC current}

In order to approach the machine nominal flux, the magnetic level must be increased. In this aim, a current $i_{s}$ constituted of a sinusoidal component $\mathrm{i}_{a c}$ superposed to a continuous component $I_{d c}$ [4], [7], [23] can be injected between two of the stator phases, according to the diagram of Fig 6. A voltage source with regulated current is required, in order to maintain constant the supply current and consequently the magnetic state of the machine, when the frequency increases.

The experiment has been realized for three continuous components $I_{d c}=1 \mathrm{~A}, I_{d c}=3 \mathrm{~A}$ and $I_{d c}=5 \mathrm{~A}$ with the same alternative current component of $350 \mathrm{~mA}$. These three tests correspond to three magnetic states of the machine. The tests have been achieved for three DC current values in order to show the influence of the magnetic state on the evolution of impedance. The maximal value of 5A is because of the supply which can't provide more. It would be interesting to make the test with $10 \mathrm{~A} \mathrm{DC}$ current which is the machine nominal current with an adapted supply. 
Fig 8 represents the variations of the norm and the argument of the neutral-phase impedance depending on the frequency for these three magnetic states. It can be noticed that the measured equivalent impedance increases with the frequency whatever the magnetic level is. In addition, there is an important variation of the amplitude depending on the magnetic state. Indeed, for a given frequency, the impedance decreases when the magnetic level increases. This kind of test allows increasing the level of the magnetic flux and at the same time it avoids the problems relied to the constant V/f ratio in SSFR test.

In Fig 9, the machine equivalent inductance decreases according to the frequency. This variation agrees with the SSFR test and shows that for fixed $\mathrm{I}_{\mathrm{dc}}$ the tests are free from the permeability effect.

\section{The induction machine models frequential identification}

The analysis of the various identification measurements showed the effect of the machine magnetic state which has an important influence on the operational impedance value and consequently on the identified model parameters. In what follows, the simulation performances of the harmonic model are compared to the experimental measurements.

The harmonic model is composed of two distinct models. The first one is classic and represents the induction machine behaviour for the fundamental frequency. Its parameters are identified using to the usual tests (TABLE I). The second model represents the frequency influence of the induction machine (Fig 1). The parameters of TABLE II are obtained with SSFR test with DC current for three magnetization currents.

The magnetization current increasing from $1 \mathrm{~A}$ to $5 \mathrm{~A}$ induces the resistances $\mathrm{R}_{1}$ ' et $\mathrm{R}_{2}$ ' diminution (respectively $31 \%$ and $59 \%)$ and also a diminution of inductance $\mathrm{L}_{2}{ }^{\prime}(53 \%)$. The strong diminution of inductance $\mathrm{L}_{1}{ }^{\prime}(79 \%)$ and the strong increasing of resistance $\mathrm{R}_{3}{ }^{\prime}(150 \%)$ lead to the equivalent impedance decreasing. It can be noticed that at $\mathrm{I}_{\mathrm{dc}}=5 \mathrm{~A}$, the parameters $\mathrm{R}_{1}$ ' and $\mathrm{L}_{1}$ ' of the harmonic model are near $\mathrm{R}_{\mathrm{S}}$ et $\mathrm{N}_{\mathrm{r}}$ ' of the usual model identified at $50 \mathrm{~Hz}$.

Fig 10 represents respectively the comparison between the measured and calculated impedances. This figure shows that the model reproduces correctly the frequential behaviour of the machine with blocked rotor for the three magnetic states identified by the three DC currents. However regarding the impedance phase the test with the highest magnetic state $(5 \mathrm{~A})$ leads to parameters allowing a better representation of the machine.

\section{Simulation}

The modelling of the induction machine associated to its identification procedure is often realised in the aim of 
numerical simulation. The circuit model of the induction machine has been developed in a simulation software (PSIM) in order to evaluate the influence of the frequential identification on the simulated line currents. The real line currents measured on the benchmark are used as reference for the comparison with the simulated results. Firstly, the measured line current drawn by the induction machine and the corresponding voltage delivered by its PWM speed drive are recorded. In this way, the real recorded voltages supply the induction machine model during the simulations. This operation allows to simulate the real operating conditions of the machine and to release some eventual differences owed to the variable speed drive. Consequently, the simulation can not take into account the possible interactions between the machine and its voltage inverter.

In what follow, the time evolutions and the frequential analysis of the simulated line currents are compared to the measurements. The speed drive operating point is $V_{\text {eff }}=230 \mathrm{~V}, f=50 \mathrm{~Hz}$ and the line current $\mathrm{I}=95 \% \mathrm{I}_{\mathrm{n}}$ of the nominal current.

Fig 11 represents the line currents simulated by the harmonic model with the parameters identified for the three magnetization levels. The time waveforms of the line currents coming from harmonic model are almost the same as the measured ones for all the DC current. Nevertheless, the current ripples are best described with the machine model determined with higher DC current. The proposed model structure (superposition principle) separates harmonics and fundamental representation. The fundamental current is obtained from the usual model which is the same for the three magnetization levels. The harmonic model impedance corresponding to each magnetization level does not influence the fundamental current amplitude. It operates only to characterize the harmonics. This good result on the fundamental component is confirmed by the spectral analysis of Fig 12 . In this figure, when the magnetization level increases, the harmonics amplitudes also increase, approaching the real levels. But, the higher magnetization level used (5A) remains insufficient to approach the real harmonics currents.

The differences between simulation and measurement can also be explained by the space harmonic generated by the induction machine (also machine design, winding, slots,...), when it rotates. These space harmonic are not taken into account in the identification because the tests are realized with a blocked rotor.

In Fig 13, line currents simulated by the harmonic model with different method of identification is presented. If the comparison is limited to the fundamental, the line current waveform obtained thanks to all the identification tests agree with measurements. Concerning the harmonics, among all the identification measurements, the SSFR with $\mathrm{I}_{\mathrm{dc}}=5 \mathrm{~A}$ leads to the best simulation result. 


\section{Conclusion}

In this article, three identification tests have been compared for the induction machine frequential modelling in order to reproduce the harmonic perturbations in the line currents. After presenting some induction machine models coming from the literature, we used a model called "harmonic" for comparing various methods of identification tests. This model is based on the superposition of two representations: the first one for the fundamental and the second one for all the other frequential components. In order to identify the model parameters, we were various kinds of identification tests have been realized on the experimental benchmark and then analyzed and discussed. The study showed the importance of keeping a constant flux during all the identification test in order to avoid the non linearity due to the variation of the magnetic permeability. Besides, we highlighted the influence of the magnetic flux level on the frequential response of the machine during tests identification.

The comparison of the measurements put in evidence the test which characterizes the best the machine. It requires the injection of sinusoidal current superposed to a continuous component in order to increase the magnetic state of the machine and to approach the nominal operating conditions.

Nevertheless, some differences exist between simulation and measurements and the accuracy of the harmonic model could be improved by taking into account the space harmonics of the induction machine. Another improving way would be building no linear model allowing the parameters evolution according to the magnetic state. 


\section{References}

[1] Vermaelen $\mathrm{C}$, “Contribution à la modélisation et à la réduction des perturbations conduits dans les systèmes d'entraînement à vitesse variable", Thesis at l'Ecole Normale Supérieure de Cachan, France, December $17^{\text {th }} 2003$.

[2] Kabbaj H, Roboam X, Lefevre Y; Faucher J, "Skin effect characterization in a squirrel cage induction machine", Proceedings of the IEEE International Symposium on Industrial Electronics, ISIE '97, volume 2, pp. 532 - 536, 7-11 July 1997.

[3] Riu D, "Modélisation des courants induits dans les machines électriques par des systèmes d'ordre $1 / 2$ "Thesis at Institut National Polytechnique de Grenoble, France, December $11^{\text {th }} 2001$.

[4] Canat S, Faucher J, "Fractional order: frequential parametric identification of the skin effect in the rotor bar of squirrel cage induction machine", ASME Design Engineering Technical Conferences 2003VIB-48393, vol. VIB-48393, 2003.

[5] Belhaj M, "Modélisation fréquentielle de la machine asynchrone en vue de l'analyse des perturbations conduites basses fréquences", Thesis at Institut de Recherche en Electrotechnique et Electronique de Nantes Atlantique (IREENA), France, June $18^{\text {th }} 2007$.

[6] IEEE Standard 115 A-(1987), "Standard procedures for obtaining synchronous machine parameters by SSFR testing".

[7] Dedene N, Pintelon R and Lataire P, "Estimation of a Global Synchronous Machine Model Using a Multiple-Input Multiple-Output Estimator”, IEEE Transaction on Energy Conversion, Vol. 18, N. 1, pp.11-16, February 2003.

[8] Viarouge P, Kamwa I, "Modélisation par circuits équivalents généralises et identification des machines électriques sur un domaine de fréquence étendu" Electrical and Computer Engineering, 1995. Canadian Conference on Vol 2, pp. 1091 - 1095, Issue, 5-8 Sep 1995.

[9] Sudhoff S.D, Aliprantis D.C, Kuhn B.T, Chapman P.L, “An induction machine model for predicting inverter machine interaction”, IEEE Transactions on Energy Conversion, vol. 17, n. 2, pp. 203 - 210, June 2002.

[10] Alwash J. H. H, Ikhwan S. H, "Generalised approach to the analysis of asymmetrical three-phase induction motors”, IEE Proceedings - Electrical Power Applications, Vol.142, No. 2, pp. 87-96, March 1995.

[11] Smith A.C, Healey R.C, Williamson S, “A transient induction motor model including saturation and deep bar effect”, IEEE Transactions on Energy Conversion, Vol. 11, nº 1, pp.8-15, March 1996.

[12] Klingshirn E.A, Jordan H.E, "Simulation of polyphase induction machine with deep rotor bars", IEEE Transactions on Power Apparatus and Systems, Vol. PAS-89, pp. 1038-1043, July/August 1970,

[13] Kamwa I, Viarouge P, “On equivalent circuit structures for empirical modeling of turbine-generator", IEEE Transaction on Energy Conversion, Vol.9, N.3, pp.579-592, September 1994.

[14] Lin J, Poinot T, Trigeassou J. C, “Modélisation et identification d'ordre non entier. Applications à une machine asynchrone et à un système thermique", Conference on Identification and Experimental Modelling, Nancy, France, pp. 151-160, 2001.

[15] Benchellal A, Bachir S, Poinot T, Trigeassou J.C, "Identification of a non-integer model of induction machines, Fractional Differentiation And its Applications”, pp. 471-482, Part 2 - Econophysics, mechanics, material modeling, thermal systems, electronics, electrical systems, 2005.

[16] Canat S, "Contribution à la modélisation dynamique d'ordre non entier de la machine asynchrone à cage", Thesis at Institut National Polytechnique de Toulouse, France, July 19 2005 , No 2241.

[17] Khaorapapong T, "Modélisation d'ordre non entier des effets de fréquence dans les barres rotoriques d'une machine asynchrone", Thesis at Institut National Polytechnique de Toulouse, France, 2001.

[18] Dandeno P L, Kundur P, Schulz R P, "Recent Trends and Progress in Synchronous Machine Modelling in the Electric Utility Industry”, Proceedings of IEEE, Vol. 62, №. 7, pp. 941-950, July 1974.

[19] Revol B, "Modélisation et optimisation des performances CEM d'une association variateur de vitesse machine asynchrone", Thesis at Université Joseph Fourier, France, November $21^{\text {th }} 2003$. 
[20] Willis J R, Brock G J, Edmonds J S, "Derivation of induction motor models from standstill frequency response tests", IEEE Transaction on Energy Conversion, Vol 4, N²4, December 1989.

[21] Moon S.I, Keyhani A, "Estimation of induction machine parameters from standstill time domain data", Industry Applications Society Annual Meeting, Conference Record of the 1993 IEEE, pp. 336-342, Issue , 2-8 Oct 1993.

[22] Retière N, "Etude des défauts dans les associations onduleur - machine asynchrone. Exemple d'une chaîne de traction", Thesis at Institut National Polytechnique de Grenoble, France, 1997.

[23] Sudhoff S.D, Aliprantis D.C, Kuhn B.T, Chapman P.L, "Experimental characterization procedure for use with an advanced induction machine model", IEEE Transactions on Energy Conversion, vol. 18, $\mathrm{n}^{\circ} .1, \mathrm{pp}$. 48-56, March 2003.

\section{List of figures}

Fig 1: Induction machine - harmonic model.

Fig 2 : Phase to neutral impedance norm and argument versus frequency at constant voltage.

Fig 3: Evolution of the magnetic induction and the permeability according to the magnetic field (sheet FeV-400-50HA).

Fig 4 : Evolution of the equivalent inductance of the IM versus frequency $(\mathrm{V}=\mathrm{cst})$.

Fig 5 : Phase to neutral impedance norm and argument versus frequency at constant $\mathrm{V} / \mathrm{f}$ ratio.

Fig 6 : Measurements device

Fig 7 : Evolution of the equivalent inductance of the IM versus frequency $(\mathrm{V} / \mathrm{f}=\mathrm{cst})$.

Fig 8 : Phase to neutral impedance norm and argument versus frequency at constant DC current.

Fig 9 : Evolution of the equivalent inductance of the IM versus frequency $(\mathrm{Idc}=\mathrm{cst})$.

Fig 10 : Phase to neutral impedance norm and argument. Tests (iac+Idc), harmonic model.

Fig 11 : Line currents simulated by the harmonic model and the measurements (Idc=cst)

Fig 12: The harmonics of the line currents simulated by the harmonic model and the measurements (Idc=cst).

Fig 13 : Line currents simulated by the harmonic model and the measurements

Fig 14 : The harmonics of the line currents simulated by the harmonic model and the measurements.

\section{List of tables}

TABLE I : Identification of the classical model parameters.

TABLE II : Parameters of the harmonic model according to the magnetization level. 


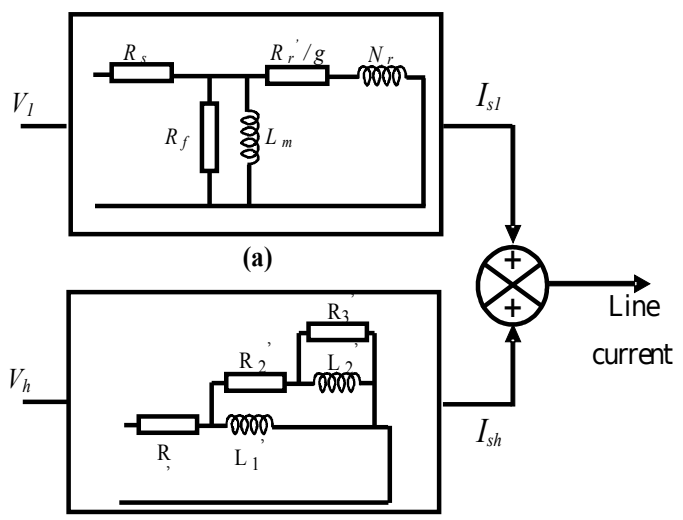

(b)

Fig 1: Induction machine - harmonic model.
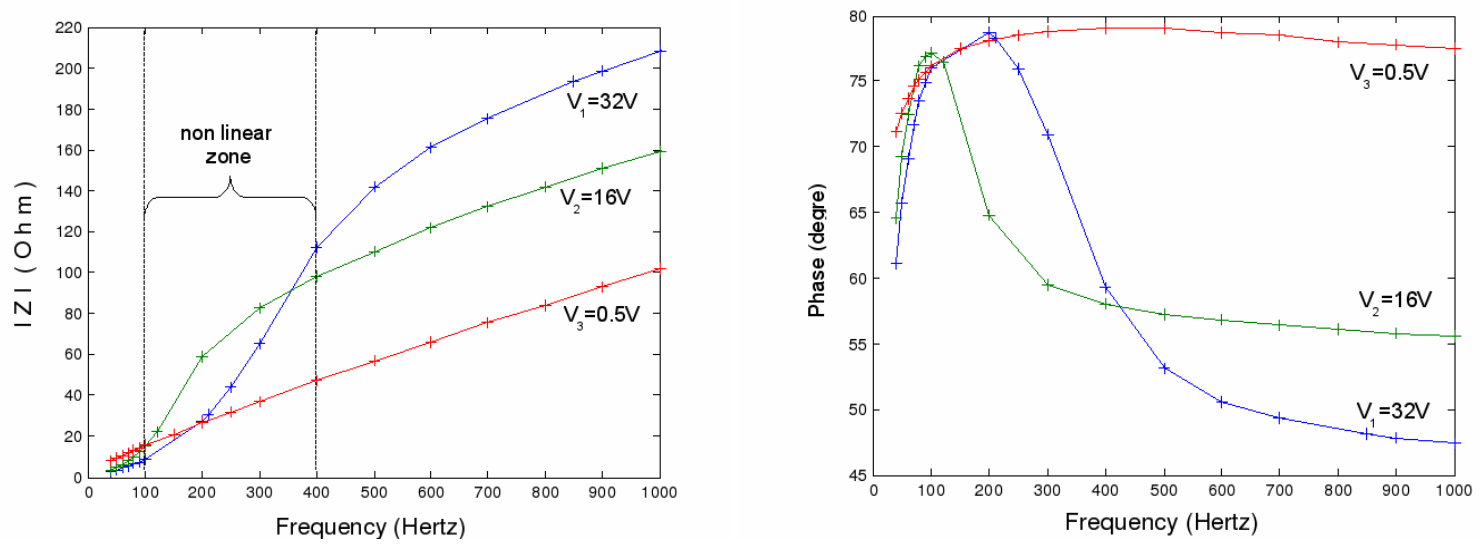

Fig 2 : Phase to neutral impedance norm and argument versus frequency at constant voltage.



Fig 3 : Evolution of the magnetic induction and the permeability according to the magnetic field (sheet FeV-400-50HA). 


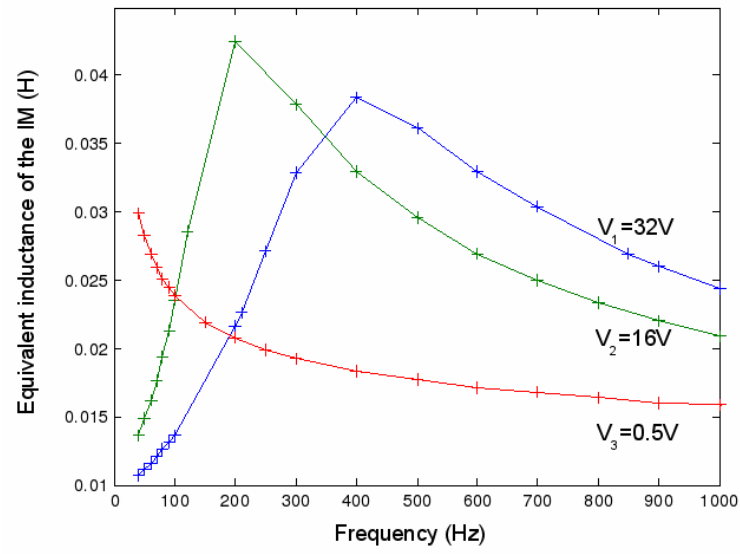

Fig 4 : Evolution of the equivalent inductance of the IM versus frequency ( $V=c s t)$.
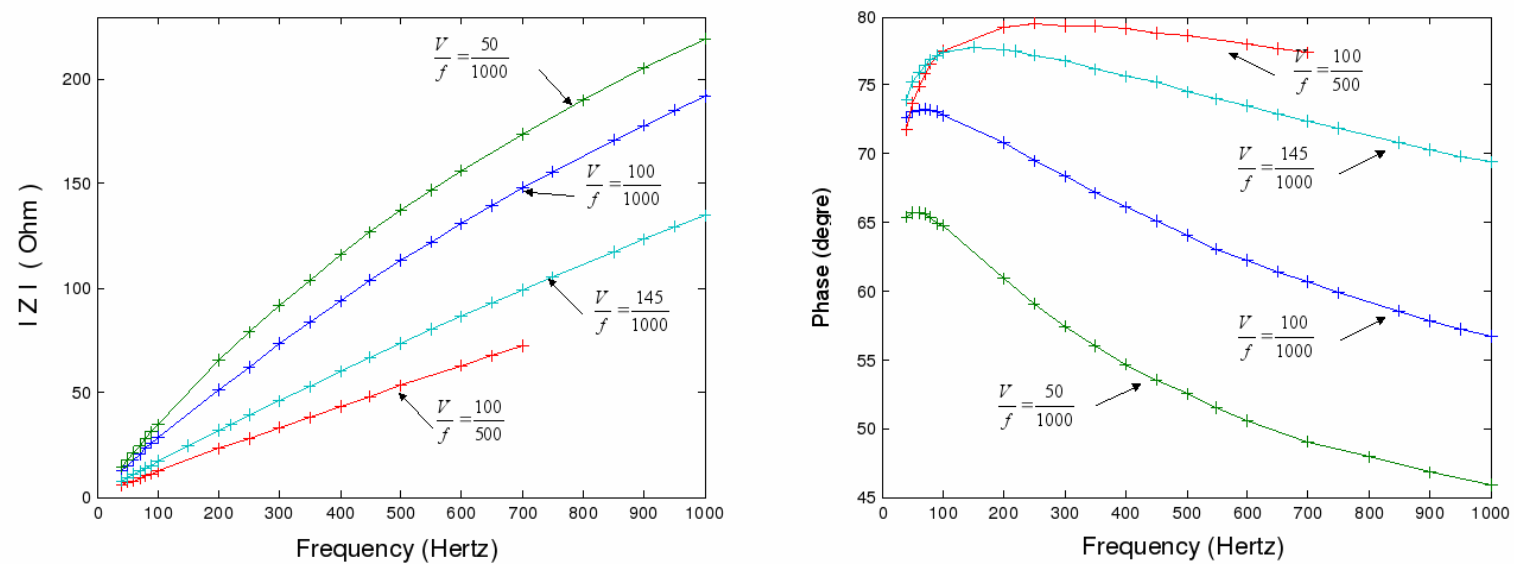

Fig 5 : Phase to neutral impedance norm and argument versus frequency at constant V/f ratio.



Fig 6 : Measurement devices 


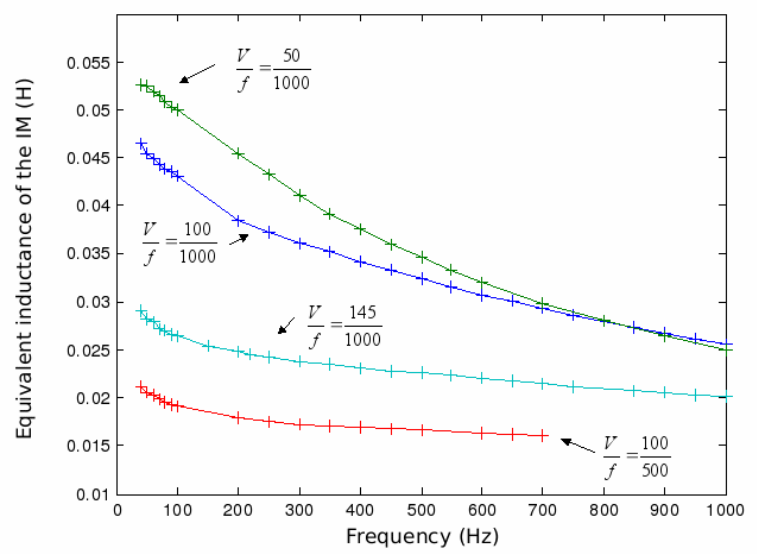

Fig 7 : Evolution of the equivalent inductance of the IM versus frequency $(\mathrm{V} / \mathrm{f}=\mathrm{cst})$.
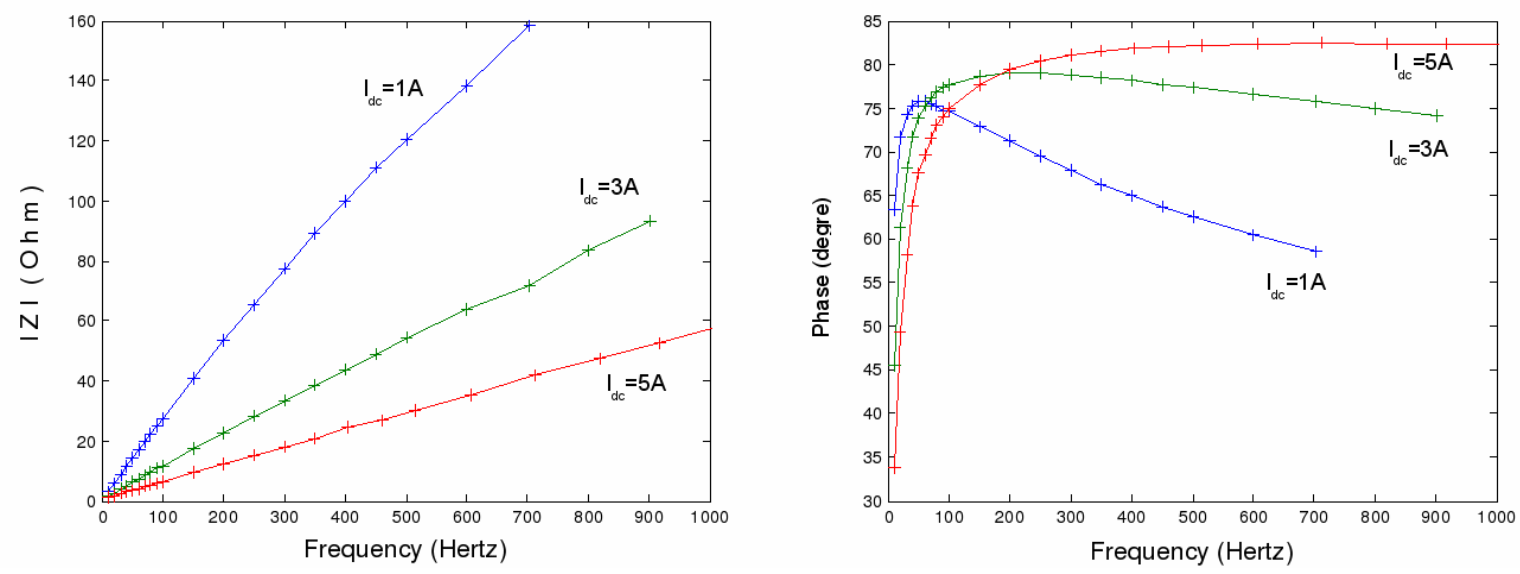

Fig 8 : Phase to neutral impedance norm and argument versus frequency at constant DC current.

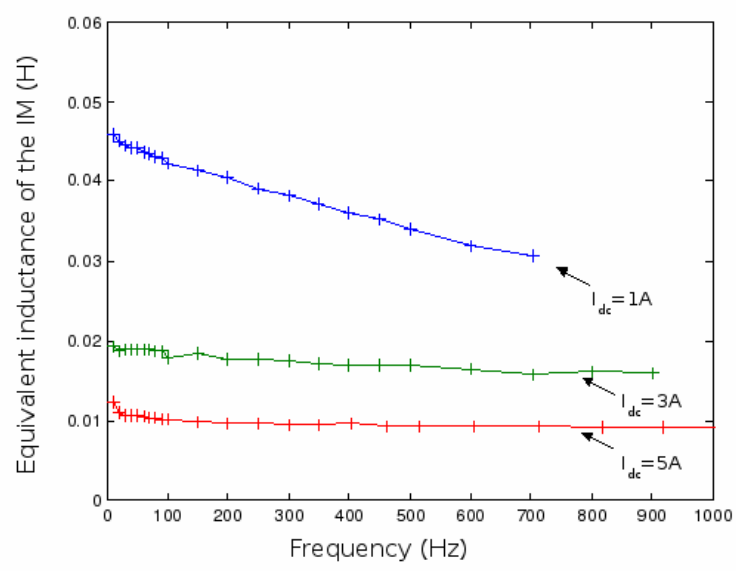

Fig 9 : Evolution of the equivalent inductance of the IM versus frequency $\left(\mathrm{I}_{\mathrm{dc}}=\mathrm{cst}\right)$. 

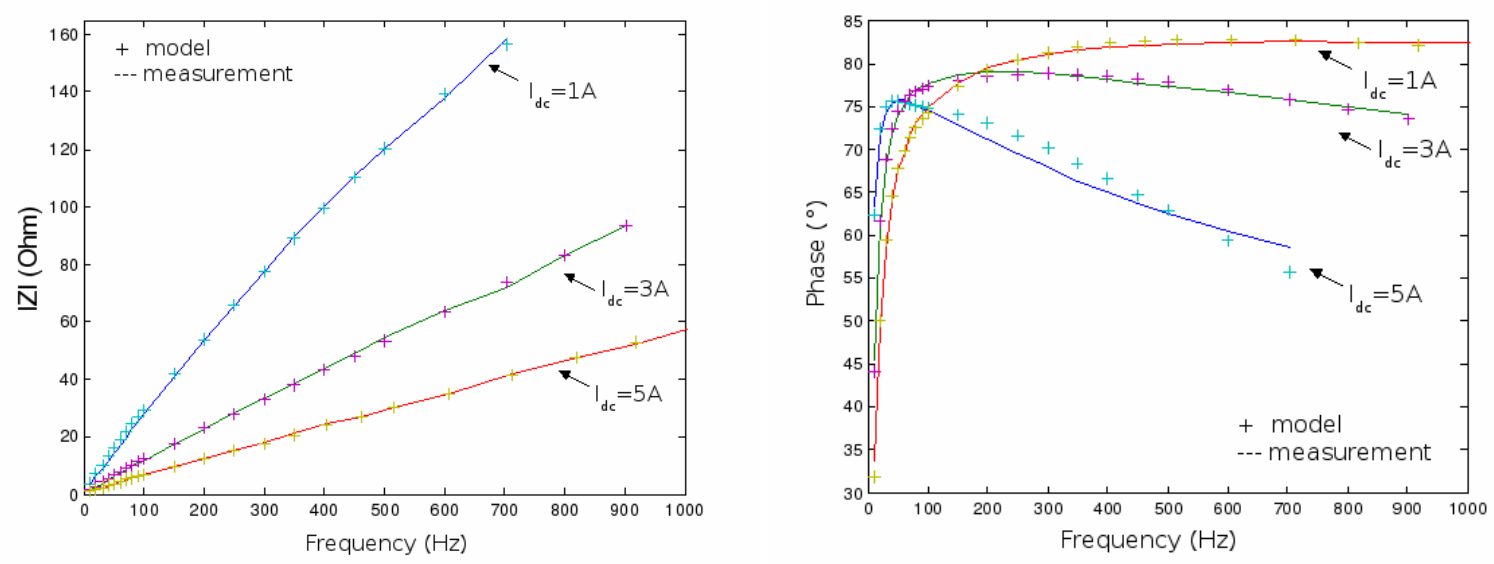

Fig 10 : Phase to neutral impedance norm and argument. Tests $\left(i_{a c}+I_{d c}\right)$, harmonic model.
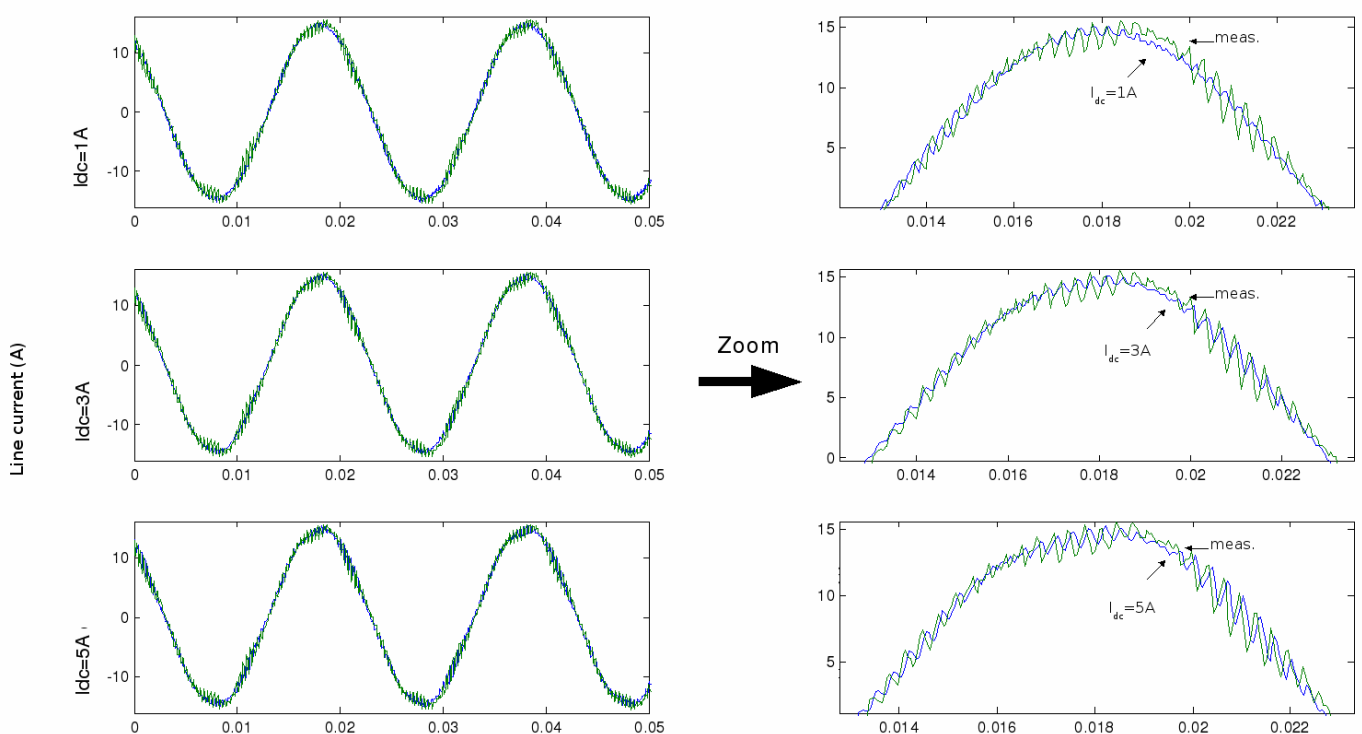

Time (s)

Fig 11 : Line currents simulated by the harmonic model and the measurements $\left(\mathrm{I}_{\mathrm{dc}}=\mathrm{cst}\right)$

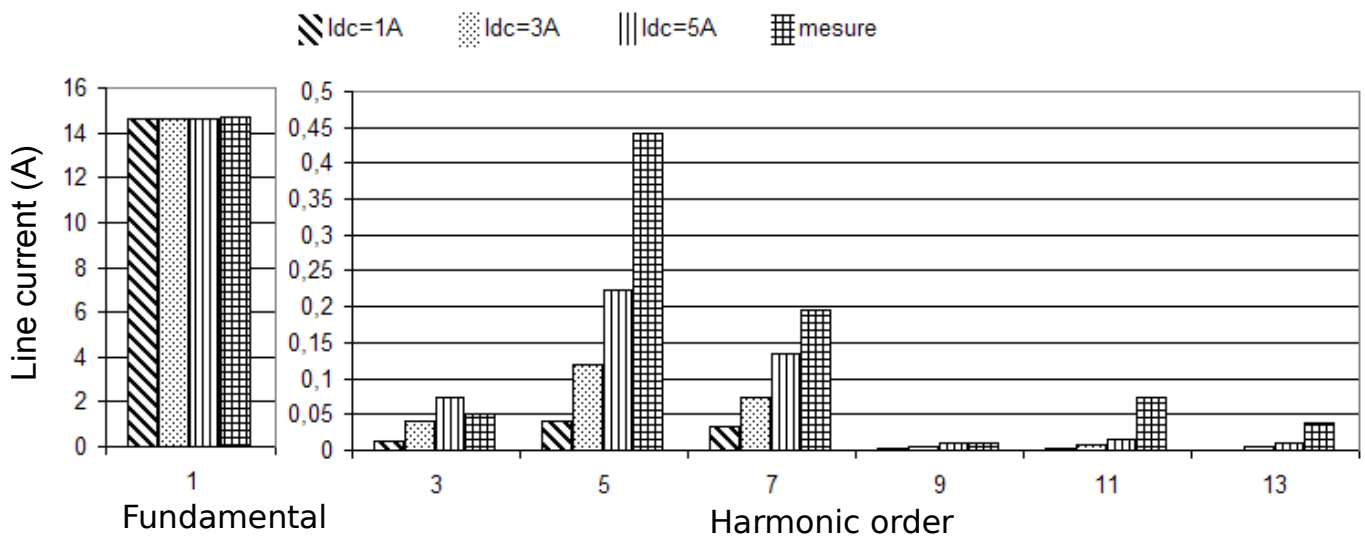

Fig 12 : The harmonics of the line currents simulated by the harmonic model and the measurements $\left(\mathrm{I}_{\mathrm{dc}}=\mathrm{cst}\right)$. 

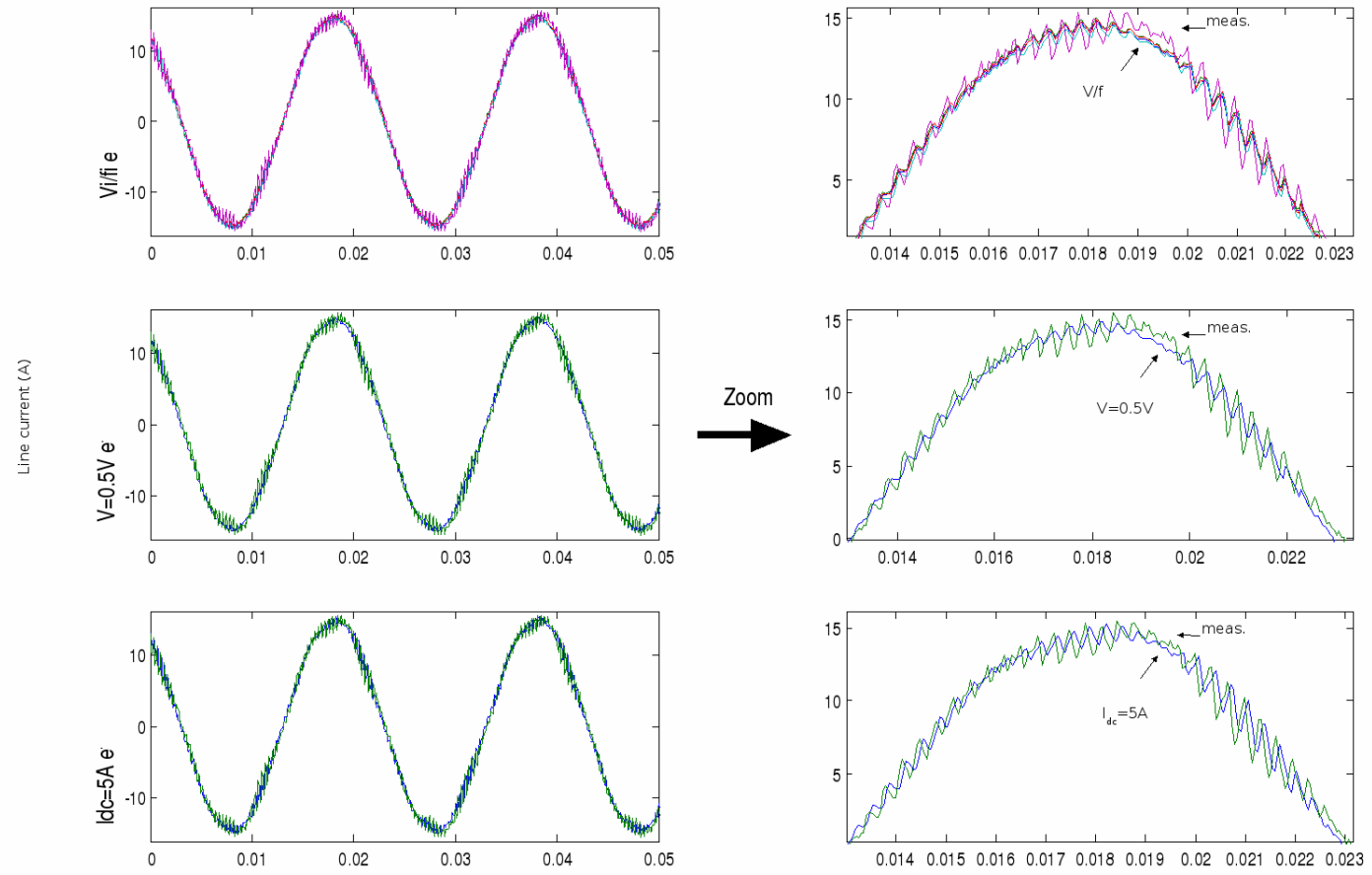

Fig 13 : Line currents simulated by the harmonic model and the measurements

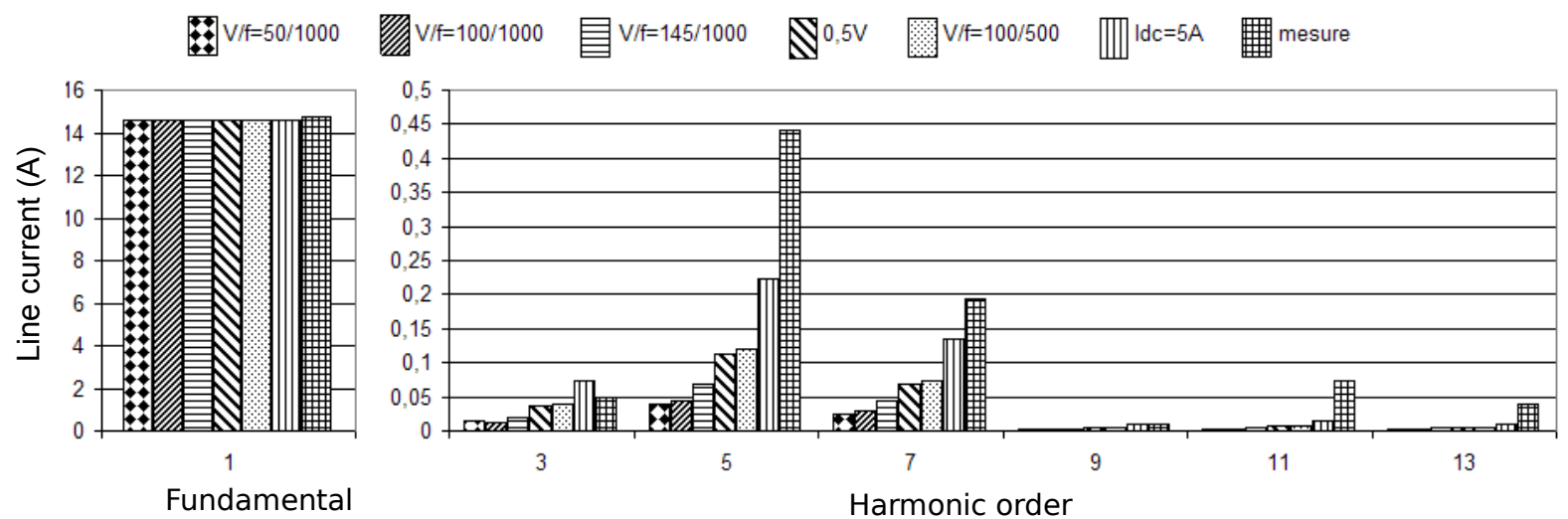

Fig 14 : The harmonics of the line currents simulated by the harmonic model and the measurements. 
TABLE I : Identification of the classical model parameters.

\begin{tabular}{|l|l|l|l|l|}
\hline$R_{s}(\Omega)$ & $N_{r}{ }^{\prime}(\mathrm{mH})$ & $R_{r}{ }^{\prime}(\Omega)$ & $L_{m}(\mathrm{mH})$ & $R_{f}(\Omega)$ \\
\hline 0.85 & 12.5 & 1.06 & 137 & 212.1 \\
\hline
\end{tabular}

TABLE II : Parameters of the harmonic model according to the magnetization level.

\begin{tabular}{|l|l|l|l|l|l|l|l|l|}
\hline & $\begin{array}{c}\mathrm{V} / \mathrm{f} \\
= \\
50 / 1000\end{array}$ & \multicolumn{1}{|c|}{$\begin{array}{c}\mathrm{V} / \mathrm{f} \\
100 / 1000\end{array}$} & $\begin{array}{c}\mathrm{V} / \mathrm{f} \\
= \\
145 / 1000\end{array}$ & $\begin{array}{c}\mathrm{V} / \mathrm{f} \\
= \\
100 / 500\end{array}$ & $\begin{array}{c}\mathrm{V} \\
= \\
0.5 \mathrm{~V}\end{array}$ & $\begin{array}{c}\mathrm{I}_{\mathrm{dc}} \\
= \\
1 \mathrm{~A}\end{array}$ & $\begin{array}{c}\mathrm{I}_{\mathrm{dc}} \\
= \\
3 \mathrm{~A}\end{array}$ & $\begin{array}{c}\mathrm{I}_{\mathrm{dc}} \\
= \\
5 \mathrm{~A}\end{array}$ \\
\hline $\mathrm{R}_{1}(\Omega)$ & 8 & 3.41 & 1.87 & 1.44 & 1.46 & 1.6 & 1.3 & 1.1 \\
\hline $\mathrm{L}_{1}(\mathrm{mH})$ & 61.4 & 47 & 27.4 & 19.8 & 21.3 & 53.2 & 20.3 & 11.1 \\
\hline $\mathrm{R}_{2}{ }^{\prime}(\Omega)$ & 204 & 171 & 162 & 101 & 100 & 88.8 & 80.8 & 36.1 \\
\hline $\mathrm{L}_{2}{ }^{\prime}(\mathrm{mH})$ & 32 & 45.3 & 52.6 & 63.7 & 64.8 & 99 & 63.1 & 46.9 \\
\hline $\mathrm{R}_{3}(\Omega)$ & 257 & 215 & 289 & 358 & 398 & 203 & 298 & 506 \\
\hline
\end{tabular}

